\title{
In Vivo Passive Axial Rotational Stiffness of the Thoracolumbar Spine
}

\author{
Victor Kosmopoulos ${ }^{*}$, Joe-Angel Lopez, James McCain and Shrawan Kumar
}

Department of Orthopaedic Surgery, University of North Texas Health Science Center, 3400 Camp Bowie Blvd, Fort Worth, TX 76107, USA

\begin{abstract}
The objective of this study was to report the passive axial rotational stiffness of the thoracolumbar spine in asymptomatic volunteers. A secondary objective was to investigate if an asymmetry exists between right and left axial rotational spine stiffness. Eighteen young asymptomatic volunteers, nine male and nine female, were tested using a previously validated axial rotational tester. Volunteers in this study were subjected to six moment magnitudes bilaterally, in a random order, and their passive axial spine rotation was measured. The results from this study showed that there is a statistically significant difference between the right $(20.3 \pm 5.8 \mathrm{Nm} / \mathrm{rad})$ and left $(17.4 \pm 4.9 \mathrm{Nm} / \mathrm{rad})$ axial rotational stiffness regardless of gender. This normative information regarding axial rotational spine stiffness can enable clinicians to assess the deviance in clinical samples and assist in treatment selection.
\end{abstract}

Keywords: In vivo, low back pain, lumbar, passive, rehabilitation, rotation, axial spine stiffness, thoracolumbar.

\section{INTRODUCTION}

Increasing spinal rotation away from the elastic equilibrium is a major risk factor for low back pain and injury [1]. Furthermore, creep within noncontractile tissues may lead to increased range of motion, altered joint mechanics and increased risk for low back pain $[2,3]$. Changes in passive spinal stiffness for example, lead to load redistributions in ligaments, muscles, and the intervertebral discs, altering movement patterns and increasing injury potential [3]. Following injury, the spine undergoes a loss of passive stiffness and stability $[4,5]$. To overcome this instability, patients indulge in guarding increasing muscle spasm and reducing motion thereby increasing the behavioral spinal stiffness [6]. Muscle co-activation activity has been reported to reduce spinal range of motion and significantly increase overall stiffness [7]. Furthermore, increased motor neuronal firing rates have been shown to increase force variability and impairing postural motion control precision required in activities of daily living $[8,9]$.

Measurement of rotational spine stiffness is therefore important for rehabilitation professionals and as input in the development of biomechanical models. Comparing normative data to low back pain patients seen in clinic may allow for a quantitative assessment of instability and help to arrive at an appropriate treatment strategy. Thus, the current study aims to report axial rotational thoracolumbar spine stiffness in asymptomatic volunteers and set a standard for comparison for rehabilitation professionals to assess deficit for establishing treatment options. A secondary objective was to investigate if an asymmetry exists between right and left axial rotational stiffness in a young asymptomatic sample.

*Address correspondence to this author at the Department of Orthopaedic Surgery, University of North Texas Health Science Center, 3400 Camp Bowie Blvd, Fort Worth, TX 76107, USA; Tel: +1 817-735-2909; Fax: +1 817-882-9242; E-mail: victor.kosmopoulos@yahoo.com

\section{METHODS}

The study was approved by a University-wide human research protection Institutional Review Board and all participants signed an informed consent form for enrollment in the study. Eighteen young asymptomatic volunteers, nine male and nine female, were recruited for this study (Table 1). The exclusion criteria included: pregnancy, cancer, spinal osteomyelitis, spinal fracture, herniated disc, ankylosing spondylitis, caudaequina syndrome, diagnosed spinal deformity, diagnosed musculoskeletal or connective tissue disorder, spinal or abdominal surgery, history of surgery involving the low back, history of receiving worker's compensation benefits, involvement in current litigation relating to a back problem, angina or congestive heart failure symptoms, history of stroke or transient ischemic attack, implantation of a cardiac pacemaker, implantation of artificial joint(s) or other fixation device(s), active bleeding or infection, use of intravenous or intramuscular or oral corticosteroids, diagnosed psychological disorders, poor general health and inability to understand and follow instructions.

Table 1. Participant Characteristics Reported as Means (Standard Deviations)

\begin{tabular}{|c|c|c|c|c|c|}
\hline Gender & $\begin{array}{c}\text { Sample } \\
\text { Size }\end{array}$ & $\begin{array}{c}\text { Age } \\
{[\mathbf{y r}]}\end{array}$ & $\begin{array}{c}\text { Weight } \\
{[\mathbf{k g}]}\end{array}$ & $\begin{array}{c}\text { Height } \\
{[\mathbf{c m}]}\end{array}$ & $\begin{array}{c}\text { BMI } \\
{\left[\mathbf{k g} / \mathbf{m}^{2}\right]}\end{array}$ \\
\hline \hline Male & 9 & $\begin{array}{c}21.1 \\
(2.6)\end{array}$ & $\begin{array}{c}79.4 \\
(18.1)\end{array}$ & $\begin{array}{c}173.6 \\
(7.6)\end{array}$ & $26.5(5.3)$ \\
\hline Female & 9 & $\begin{array}{c}20.8 \\
(2.0)\end{array}$ & $\begin{array}{c}65.5 \\
(12.1)\end{array}$ & $\begin{array}{c}163.1 \\
(4.7)\end{array}$ & $24.7(4.6)$ \\
\hline
\end{tabular}

The volunteers were attired in loose clothing and seated upright in a previously described and validated Axial Rotation Tester (AROT) [10]. The device and testing setup were designed to minimize any possible flexion/extension of the trunk while allowing for axial rotation and coupled lateral flexion. The lower extremities of the volunteers, hip down, were stabilized with four Velcro belts fastened tightly 
across the pelvis, distal thighs, proximal tibias and at the ankles, thus restricting any motion mediated through the lower extremities.

A shoulder harness was fitted on the shoulders of the participants and tightened for a snug fit. The shoulder harness was rigidly fixed to an overhead circular pulley (35 $\mathrm{cm}$ diameter) which accommodated a tension cable. The tension cable ran behind the subject horizontally in a straight line going over another pulley $50 \mathrm{~cm}$ away such that its groove was at the same height as the groove of the overhead pulley. At the end of this tension cable there was a load receptacle allowing for the placement of varying loads to exert predetermined rotational moments on the thoracolumbar spine. Volunteers in this study were subjected to moments of $3.7 \mathrm{Nm}, 7.3 \mathrm{Nm}, 11.0 \mathrm{Nm}, 14.7 \mathrm{Nm}, 18.4 \mathrm{Nm}$, and $22.0 \mathrm{Nm}$ bilaterally, in a random order, perpendicular to the spinal axis. The angular rotation of the spine corresponding to each of these applied moments was measured using a high precision potentiometer (MCP30, P3 America, Inc., San Diego, CA). The applied moments for each patient in each direction (i.e., right and left axial rotation) were plotted against the recorded angular rotation and the rotational stiffness (in $\mathrm{Nm} / \mathrm{rad}$ ) was defined as the slope of a best fit linear regression line.

A paired samples t-test was used to test the hypothesis that there is no significant difference between the right and left rotational stiffness within each participant. Furthermore, to investigate if this is consistent across participants a Pearson correlation was performed. To test the hypothesis that no significant differences exist in rotational stiffness between male and female participants, an independent samples
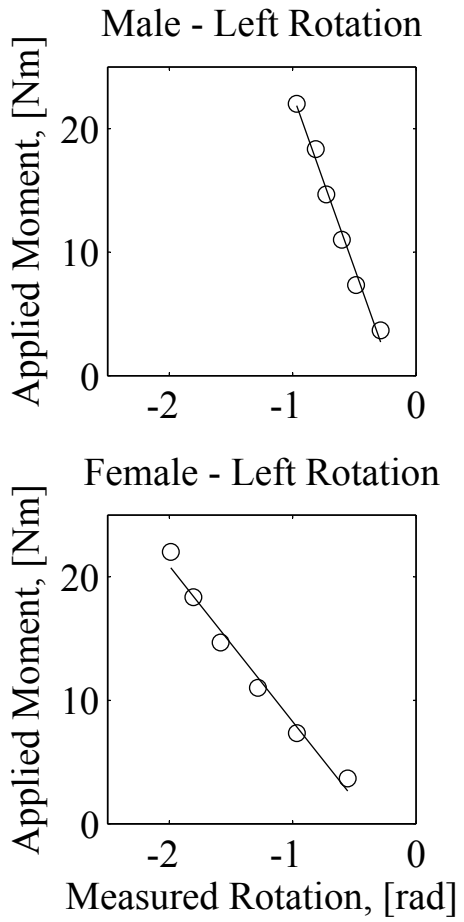

t-test was used. To test the equal variance assumption, Levene's Test was first performed. Finally, linear regression analyses were performed to identify if correlations exist between axial rotational stiffness and age, weight, height, or body mass index (BMI).

\section{RESULTS}

Plotting the applied moments as a function of measured angular rotation for each volunteer resulted in a highly predictive linear regression with average $R^{2}$ values of 0.96 for both the right and left rotational stiffness regardless of gender (Fig. 1). The average left rotational stiffness $(17.4 \pm$ $4.9 \mathrm{Nm} / \mathrm{rad}$ ) was less that that measured when participants were loaded/rotated to the right $(20.3 \pm 5.8 \mathrm{Nm} / \mathrm{rad})$ (Fig. 2a). This difference was statistically significant when comparing right and left axial rotational stiffness within each participant $(p=0.010)$. Furthermore, results show that the participants consistently had lower left, as compared to right, axial rotational stiffness as measured using Pearson's correlation $(\mathrm{p}=0.001)$.

Looking at differences between male and female volunteers, Levene's test confirmed that the groups did have equal variances for the right $(p=0.106)$ and the left $(p=$ 0.388 ). Males had a higher average rotational stiffness than females for both the right side $(22.6 \pm 6.0 \mathrm{vs} .17 .9 \pm 4.7$ $\mathrm{Nm} / \mathrm{rad})$ and the left $(19.6 \pm 5.0$ vs. $15.3 \pm 4.0 \mathrm{Nm} / \mathrm{rad})($ Fig. $\mathbf{2 b - c ) . ~ T h i s ~ d i f f e r e n c e ~ i n ~ r o t a t i o n a l ~ s t i f f n e s s ~ o b s e r v e d ~ b e t - ~}$ ween males and females however, was not statistically different for either the right $(\mathrm{p}=0.085)$ or the left side $(\mathrm{p}=$ $0.061)$. Finally, the regression analyses did not identify any

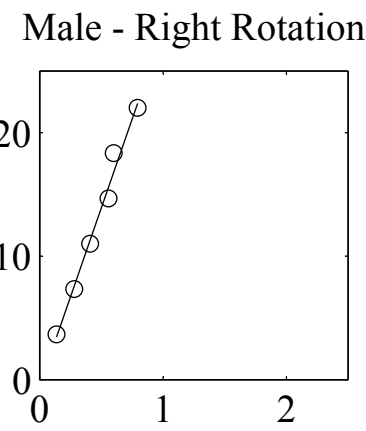

Female - Right Rotation

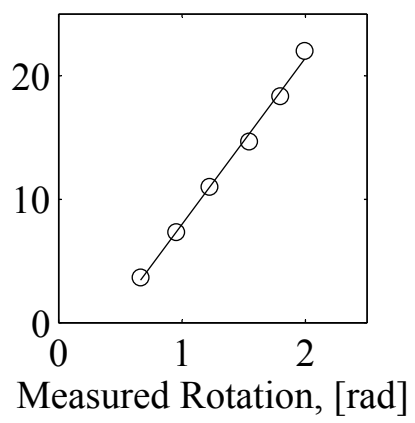

Fig. (1). These plots show an illustrative example of the highly predictive linear regression analysis of the applied moments as a function of measured angular rotation for a male $(\mathbf{A}, \mathbf{B})$ and a female volunteer $(\mathbf{C}, \mathbf{D})$. The resulting $\mathrm{R}^{2}$ values for the male and female volunteers displayed, rotating to the left, were 0.987 (A) and 0.981 (C), respectively. Rotation to the right resulted in $\mathrm{R}^{2}$ values of 0.985 (B) for the male, and 0.996 (D) for the female participant. 
significant predictive correlation between measured rotational stiffness and participant age, weight, height, or BMI.

\section{ALL PARTICIPANTS}
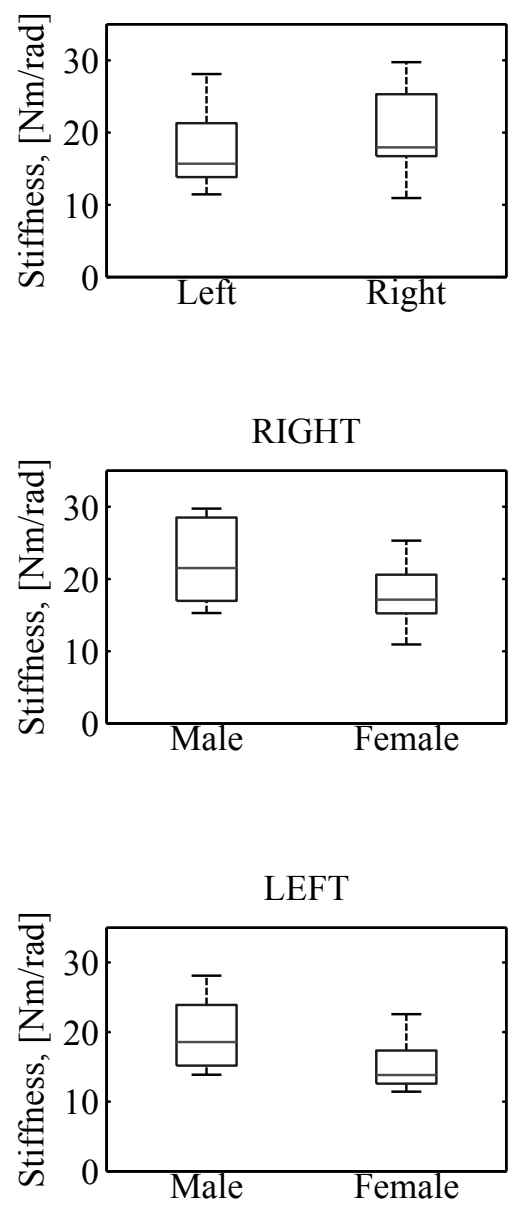

Fig. (2). This boxplot visually illustrates differences in left and right axial rotational spinal stiffness for all the participants (A) and the right (B) and left $(\mathbf{C})$ rotational stiffness between male and female participants. The line inside the box is the median, the edges of the box represent the 25 th and 75 th percentiles, and the whiskers extend to the extreme data points giving the resulting range.

\section{DISCUSSION}

Increasing levels of muscle co-activation have been suggested to be an objective indicator of passive instability of the lumbar spine [11]. Spinal instability may lead to excessive and possibly unbalanced load sharing for the passive structures, abnormal motion, and thus changes in spinal stiffness and stress concentration. In vivo assessments, including estimates of spinal stiffness, provide outcome measures that may help clinicians assess deviance and select appropriate treatment strategies for patients with spinal disorders [12]. In this study we report on passive axial rotational spinal stiffness in a young asymptomatic sample with the aim of setting a standard for comparison to be used by rehabilitation professionals. Our findings showed a significant asymmetric difference between the right and left rotational spine stiffness of participants regardless of gender.
The right axial rotational stiffness was consistently greater than that measured as participants rotated to the left. Furthermore, although not statistically different, the mean stiffness measured in male participants, rotating both to the right and left, was greater than that of female participants. However, due to a small sample size this population trait is hard to determine based on the results presented here.

The spinal stiffness asymmetry found in this study may be a factor of daily activities requiring asymmetrical loading of the spine. Asymmetrical tasks have been suggested to increase antagonist muscle co-activation and lead to a shift in spinal torsional and lateral shear stresses [13, 14], in time changing the mechanical properties of passive spinal tissues. Interestingly, although the sample studied was young, asymptomatic, and prescreened to eliminate those experiencing back pain, the movements leading to this measured asymmetry may be a future risk factor for development of low back pain [15]. Gombatto and colleagues examined differences in passive spinal tissue characteristics between people with and without low back pain [13]. Interestingly, although using a passive lateral bending protocol, they found that participants without low back pain did demonstrate some degree of asymmetry in movement patterns. Furthermore, when compared to the low back pain subjects, the degree of asymmetry increased significantly. This asymmetry may thus be an important factor to consider when determining a treatment strategy [13]. In fact, studies have shown that lumbar passive tissue properties can be increased or decreased with an appropriate exercise program [1].

Other studies have reported on the stiffness of the spine in flexion/extension [1, 3, 16, 17], lateral bending [13, 17], axial rotation [17, 18], and with combined motions [19]. Focusing on rotation, van Deursen and colleagues using a biomechanical model studied the mechanical response of the spine to small alternating rotary pelvic stimulation [18]. Using this simplified model, they found that even minor stimulation is sufficient to mobilize the intervertebral joints producing a significant spinal rotational response. This mobilization was suggested to enhance fluid exchange in the intervertebral disc improving its nutritional status. In terms of rotational stiffness, McGill and colleagues studied the in vivo effects of wearing an abdominal belt and of full breath inhalation [17]. They concluded that both belt wearing and holding one's breath stiffened the torso in the axial rotational axis of the spine.

In conclusion, tissue strain and risk of injury increase as a function of axial rotation away from the spine's elastic equilibrium [1]. This study aimed to report the passive axial rotational stiffness of the spine as an outcome measure for future biomechanical models and for the treatment of spinal disorders. Although this study does not include a low back pain subgroup, it does offer normative information regarding axial rotational spine stiffness and presents the importance of early detection of asymmetries as something clinicians may use when considering appropriate treatment, including preventative, strategies.

\section{CONFLICT OF INTEREST}

None declared. 


\section{ACKNOWLEDGEMENT}

The authors wish to acknowledge Sejong Bae, PhD Director of Biostatistical Services at the University of North Texas Health Science Center - for his assistance with the statistics described in this study, and Robert Longnecker, M.S. - Laboratory Manager of the Osteopathic Heritage Foundation Physical Medicine Core Research Facility - for his technical support.

\section{REFERENCES}

[1] Scannell JP, McGill SM. Lumbar posture-should it and can it, be modified? A study of passive tissue stiffness and lumbar position during activities of daily living. Phys Ther 2003; 83: 907-17.

[2] Dolan P, Adams MA. Repetitive lifting tasks fatigue the back muscles and increase the bending moment acting on the lumbar spine. J Biomech 1998; 31: 713-21.

[3] Parkinson RJ, Beach TA, Callaghan JP. The time-varying response of the in vivo lumbar spine to dynamic repetitive flexion. Clin Biomech 2004; 19: 330-6.

[4] Oxland TR, Crisco JJ III, Panjabi MM, Yamamoto I. The effect of injury on rotational coupling at the lumbosacral joint. A biomechanical investigation. Spine 1992; 17: 74-80.

[5] Panjabi MM. The stabilizing system of the spine. Part I. Function, dysfunction, adaptation, and enhancement. J Spinal Disord 1992; 5: 383-9.

[6] Bergmark A. Stability of the lumbar spine. A study in mechanical engineering. Acta Orthop Scand Suppl 1989; 230: 1-54

[7] Quint U, Wilke HJ, Shirazi-Adl A, Parnianpour M, Loer F, Claes LE. Importance of the intersegmental trunk muscles for the stability of the lumbar spine. A biomechanical study in vitro. Spine 1998; 23: $1937-45$
[8] Hamilton AF, Jones KE, Wolpert DM. The scaling of motor noise with muscle strength and motor unit number in humans. Exp Brain Res 2004; 157: 417-30.

[9] Jones KE, Hamilton AF, Wolpert DM. Sources of signal-dependent noise during isometric force production. J Neurophysiol 2002; 88 : $1533-44$

[10] Kumar S. Isolated planar trunk strength and mobility measurement for impaired and normal backs: Part I-The Devices. Int J Ind Ergon 1996; 17: 81-90.

[11] Cholewicki J, Panjabi MM, Khachatryan A. Stabilizing function of trunk flexor-extensor muscles around a neutral spine posture. Spine 1997; 22: 2207-12.

[12] Keller TS, Colloca CJ, Harrison DE, Moore RJ, Gunzburg R. Muscular contributions to dynamic dorsoventral lumbar spine stiffness. Eur Spine J 2007; 16: 245-54.

[13] Gombatto SP, Norton BJ, Scholtes SA, Van Dillen LR. Differences in symmetry of lumbar region passive tissue characteristics between people with and people without low back pain. Clin Biomech 2008; 23: 986-95.

[14] Marras WS, Mirka GA. A comprehensive evaluation of trunk response to asymmetric trunk motion. Spine 1992; 17: 318-26.

[15] Marras WS, Lavender SA, Leurgans SE, et al. Biomechanical risk factors for occupationally related low back pain disorders. Ergonomics 1995; 38: 377-410.

[16] Beach TA, Parkinson RJ, Stothart JP, Callaghan JP. Effects of prolonged sitting on the passive flexion stiffness of the in vivo lumbar spine. Spine J 2005; 5: 145-54.

[17] McGill S, Seguin J, Bennett G. Passive stiffness of the lumbar torso in flexion, extension, lateral bending, and axial rotation. Effect of belt wearing and breath holding. Spine 1994; 19: 696-704.

[18] van Deursen DL, Lengsfeld M, Snijders CJ, Evers JJ, Goossens RH. Mechanical effects of continuous passive motion on the lumbar spine in seating. J Biomech 2000; 33: 695-9.

[19] Drake JD, Callaghan JP. Do flexion/extension postures affect the in vivo passive lumbar spine response to applied axial twist moments? Clin Biomech 2008; 23: 510-9.

This is an open access article licensed under the terms of the Creative Commons Attribution Non-Commercial License (http://creativecommons.org/licenses/bync/3.0/), which permits unrestricted, non-commercial use, distribution and reproduction in any medium, provided the work is properly cited. 